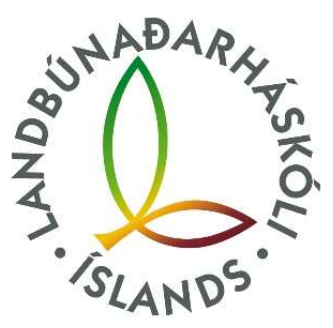

อे Opin vísindi

This is not the published version of the article / petta er ekki útgefna útgáfa greinarinnar

Author(s)/Höf.: $\quad$ Nicholas Rosenstock, Magnus Ellström, Edda Oddsdottir, Bjarni D. Sigurdsson, Håkan Wallander,

Title/Titill: $\quad$ Carbon sequestration and community composition of ectomycorrhizal fungi across a geothermal warming gradient in an Icelandic spruce forest

Year/Útgáfuár:

2019

Version/Útgáfa: $\quad$ Article in press / lokaútgáfa höfundar

Please cite the original version:

Vinsamlega vísið til útgefnu greinarinnar:

Nicholas Rosenstock, Magnus Ellström, Edda Oddsdottir, Bjarni D. Sigurdsson, Håkan Wallander, "Carbon sequestration and community composition of ectomycorrhizal fungi across a geothermal warming gradient in an Icelandic spruce forest," in Fungal Ecology, vol. 40, pp. 32-42, https://doi.org/10.1016/j.funeco.2018.05.010.

Rights/Réttur: $\quad$ (C) 2018 Elsevier Ltd and British Mycological Society. 
Methodological Advances

\title{
Carbon sequestration and community composition of ectomycorrhizal fungi across a geothermal warming gradient in an Icelandic spruce forest
}

\author{
Nicholas Rosenstock ${ }^{\text {a, b, * }}$, Magnus Ellström ${ }^{\text {a }}$, Edda Oddsdottir ${ }^{c}$, Bjarni D. Sigurdsson ${ }^{\text {d, }}$ \\ Håkan Wallander ${ }^{\mathrm{a}}$ \\ a MEMEG, Department of Biology, Lund University, 223 62, Lund, Sweden \\ b Center for Environmental and Climate Research, Lund University, 223 62, Lund, Sweden \\ ' Icelandic Forest Research, Mógilsá, 116 Reykjavik, Iceland \\ 'Agricultural University of Iceland, Hvanneyri, 311 Borgarnes, Iceland
}

\section{A R T I C L E I N F O}

\section{Article history}

Received 1 December 2017

Received in revised form

29 April 2018

Accepted 28 May 2018

Available online $\mathrm{xxx}$

Corresponding Editor: Jan Jansa

\section{Keywords:}

Ectomycorrhiza

Climate change

Soil warming

Picea sitchensis

Carbon sequestration

Pyronemataceae

Wilcoxina

\begin{abstract}
A B S T R A C T
Soil warming $\left(0-5.5^{\circ} \mathrm{C}\right.$ above controls) effects on ectomycorrhizal growth, carbon sequestration and community composition were examined in a Picea sitchensis forest spanning a geothermal gradient in Iceland. Fungal communities were assayed with sand-filled ingrowth meshbags incubated in the soil for 5 months. Meshbags amended with compost made from maize leaves (a C4 plant enriched in ${ }^{13} \mathrm{C}$ ) were incubated for 5 or 12 months and used to estimate $C$ sequestration by the fungal community. Despite increases in tree growth, moderate warming only slightly reduced or had no effect on mycelial growth and had no effect on fungal carbon sequestration or overall ectomycorrhizal community composition. Warming was associated with increased abundance of ascomycetes, particularly pyronemataceous ectomycorrhizal fungi, and altered saprotrophic community composition. Increased nitrate availability and root turnover may explain the lack of a positive ectomycorrhizal growth response to increased tree growth and observed shifts in community composition with warming
\end{abstract}

(c) 2018 Elsevier Ltd and British Mycological Society. All rights reserved.

\section{Introduction}

Global change has elevated temperatures by $\sim 1.5^{\circ} \mathrm{C}$ (Moritz et al., 2002) in northern ecosystems and an additional $4-7^{\circ} \mathrm{C}$ increase is expected by 2100 (IPCC climate change 2007). These temperature increases may have profound effects on plant productivity and soil carbon cycling, and many warming experiments have been performed to investigate these effects, which have in turn been the subject of several meta-analyses (Rustad et al., 2001; Wu et al., 2011; Dieleman et al., 2012). Soil respiration, net $\mathrm{N}$ mineralization, and plant productivity have generally increased and soil moisture decreased in response to warming. The balance between carbon gain through plant growth and carbon loss

\footnotetext{
* Corresponding author. Center for Environmental and Climate Research, Lund University, 223 62, Lund, Sweden.
}

E-mail address: rosenstockn@gmail.com (N. Rosenstock). through respiration will determine to what extent an ecosystem will experience a net gain or loss of carbon. It is of utmost importance to understand the outcome of these opposing processes in order to predict the effect of global change on carbon cycling, especially in northern ecosystems (Davidson and Janssens, 2006).

Ectomycorrhizal fungi (EMF) dominate boreal, temperate, and many arctic ecosystems, and these fungi are essential contributors to nutrient and carbon cycling (Smith and Read, 2008). Up to 50\% of annual primary production can be allocated to EMF (Simard et al. 2002), and biomass production and turnover of EMF mycelia represent a large influx to the soil carbon cycle. EMF necromass turns over much more slowly than biomass (Schweigert et al., 2015; Ekblad et al., 2016), and soil organic matter may to a large extent be composed of fungal necromass (Langley and Hungate, 2003; Godbold et al., 2006; Cairney, 2012; Clemmensen et al., 2013; Ekblad et al., 2013).

In a recent meta-analysis, Mohan et al. (2014) investigated the 
effects of global change factors on mycorrhizal parameters and found that $60 \%$ of the studies showed increased EMF abundance in response to warming. These effects may be direct, through enhanced metabolism of EMF (Staddon et al., 2002; Kivlin et al., 2013), or indirect, through changes in plant performance (Rygiewicz et al., 2000; Staddon et al., 2002). Elevated temperatures may also enhance growth of EMF due to a longer growing season (Majdi and Öhrvik, 2004; Leppälanni-Kuransuu et al., 2013), or due to enhanced abundance of EM hosts, which in turn may influence EMF abundance and growth in the soil (Clemmensen et al., 2006). Negative effects of warming on EMF abundance have also been found ( $17 \%$ of the studies in the meta-analysis performed by Mohan et al., 2014). This could be an effect of reduced soil moisture in response to warming. Interactive effects between soil moisture and warming treatments on EMF growth have been repeatedly observed (Lin et al., 2010; Geml et al., 2015; Peltoniemi et al., 2015); Lin et al. (2010) observed that EMF growth in xeric sites responded negatively to soil warming while EMF growth in mesic sites responded positively.

In boreal and temperate forests EMF communities are species rich, with over 50 species commonly reported (Wallander et al., 2010; Pickles et al., 2012a) and over 100 taxa occasionally reported from monodominant forest stands (Tedersoo et al., 2006; Parrent and Vilgalys, 2007). The drivers maintaining this diversity and the ecological niches of these taxa remain largely unknown, but soil chemistry, depth, moisture and nutrient availability have all been observed to influence EMF community composition (Bruns, 1995; Shi et al., 2002; Rosenstock et al., 2016; Pena et al., 2017). Studies examining plant performance with different EMF symbionts have revealed functional variation between EMF species in regard to plant growth (Siemens and Zwiazek, 2008; Jones et al., 2010), drought resistance (di Pietro et al., 2007), and recalcitrance in soil (Fernandez and Koide, 2014; Fernandez et al., 2016). Soil warming may also change the composition of the EMF community, which in turn may influence carbon sequestration rates in the soil. For instance, Deslippe at al. (2012) found greater abundance of EMF species belonging to Cortinarius, with capacity to degrade organic matter to obtain $\mathrm{N}$, in response to warming of arctic soils. Clemmensen et al. (2015) found that early successional stages of coniferous forests in northern Sweden were dominated by longdistance EMF exploration types with a high capability to degrade organic matter to obtain $\mathrm{N}$, while later successional forests were dominated by melanin-rich EMF and ericoid mycorrhizal fungi, potentially contributing to higher rates of carbon accumulation.

The predicted temperature increases in high latitude forest ecosystems dominated by ectomycorrhizal trees, the functional diversity of EMF communities, and the importance of EMF for ecosystem carbon sequestration, highlight the need for a better understanding of EMF responses to elevated temperatures, in terms of both growth and community composition, in order to predict how global change will affect carbon cycling in soils (Pickles et al., 2012b; Kivlin et al., 2013).

Studies of warming effects on EMF to date have suffered from methodological drawbacks that have limited their utility for predicting the effects of climate change on EMF. The majority of existing research on warming effects on soil fungi arise from open top chamber warming experiments. These treatments tend to achieve a relatively moderate level of warming $\left(<2{ }^{\circ} \mathrm{C}\right)$, and have been associated with treatment artifact effects such as reduced wind or light, altered soil moisture, limited soil heating and altered temperature extremes (Marion et al., 1997; Sharkhuu et al., 2013). Many of the remaining studies utilize resistance cables buried in the soil to achieve $0-5{ }^{\circ} \mathrm{C}$ warming of the soil. This approach carries the drawback of the disturbance associated with burying the cables, though this can be controlled for. Both of these warming treatments are generally conducted with a single warming treatment, and may thus have less explanatory power than a warming gradient. Geothermally active areas offer long-lasting, continuous and often wide soil temperature gradients with the potential to overcome these drawbacks (Sigurdsson et al., 2016).

In the present study, a planted Picea sitchensis forest stand in a geothermally warmed area in Iceland was used to study effects of elevated soil temperatures on EMF growth and community composition, as well as EMF induced carbon sequestration using ingrowth meshbags according to the method described in Wallander et al. (2011). The gradient covered temperatures from ambient to $50^{\circ} \mathrm{C}$ above ambient but most of our measurements were performed between ambient and $6^{\circ} \mathrm{C}$ above ambient since trees died at higher temperatures. The presence of the thermal gradient had been evident for $5 \mathrm{y}$ when the study was done. We expected optimal growth of EMF at intermediate elevated temperatures, and we expected the EMF community to shift in response to warming. Furthermore, we expected EMF induced carbon sequestration to increase in response to abundance of melanin-rich species, and to decline in response to abundance of EMF species with a documented capacity to decompose organic matter.

\section{Material and methods}

\subsection{Study sites}

This study was conducted at the ForHot research site, which is located in the Hengill geothermal area, $40 \mathrm{~km}$ east of Reykjavik, Iceland $\left(64^{\circ} 00^{\prime} 01^{\prime \prime} \mathrm{N}, 21^{\circ} 11^{\prime} 09^{\prime \prime} \mathrm{W} ; 75-116 \mathrm{~m}\right.$ a.s.l.). The average temperature between 2004 and 2014 in the nearby village Eyrarbakki was $5.2^{\circ} \mathrm{C}$, and average daily minimum and maximum temperatures were 2.2 and $8.6^{\circ} \mathrm{C}$. The average yearly precipitation during the same period was $1431 \mathrm{~mm}$ (Icelandic Meteorological Office). The ForHot forest research site was planted with $P$. sitchensis in 1966-1967, and the dominant trees had reached a height of $9.9 \mathrm{~m}$ in 2011. The plantation is dense and almost no vegetation is present in the field layer.

The plantation area has been warmed since May 2008, when an earthquake shifted a geothermal system under previously unwarmed soils. The soil warming was caused by heat conduction from the underlying bedrock that is warmed from below by hot groundwater. The soil warming increment was relatively constant throughout the year and extreme deviations were exceptional (Sigurdsson et al., 2016). No signs of soil contamination by geothermal byproducts were found and no significant changes in $\mathrm{pH}$ or soil moisture occurred along the warming gradients (Sigurdsson et al., 2016). The underlying soil is a Silandic Andosol. More background data of the site is available in Sigurdsson et al. (2016).

Four transects were established in the forest in 2010 . Ten $1 \times 1$ $\mathrm{m}^{2}$ plots were established along each of the transects to cover temperatures ranging from ambient to around $50^{\circ} \mathrm{C}$ above ambient (Fig. 1). All trees died in the two plots with the highest temperatures $\left(9-50^{\circ} \mathrm{C}\right.$ above ambient) within each transect, but no mortality was observed in the first 8 plots, which covered a temperature range from ambient to around $5.5^{\circ} \mathrm{C}$ above ambient. Soil temperature was recorded with a temperature probe at $5 \mathrm{~cm}$ depth in October 2012 when the meshbags incubated for 5 months were collected.

\subsection{Experimental design}

Two types of fungal ingrowth meshbags were installed in the plots along the transects in May 2012. The bags were triangular 


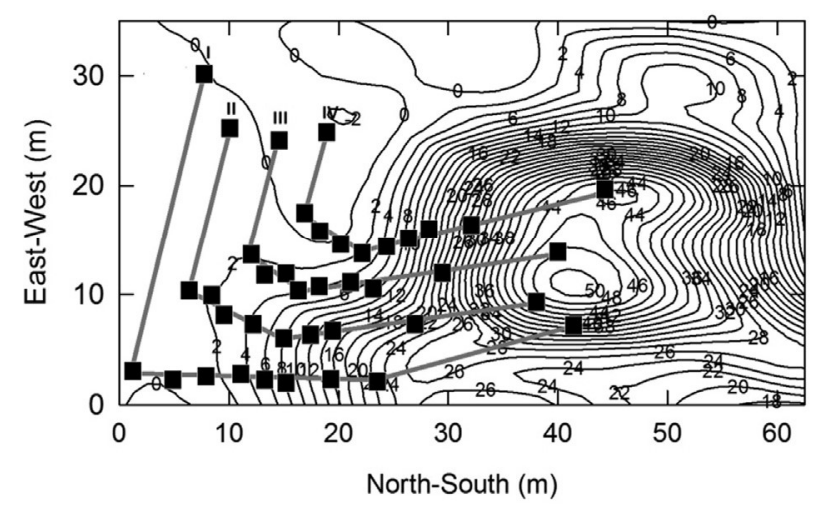

Fig. 1. Map of the 4 transects (I-IV) and study plots with contour lines denoting degrees of soil warming at $10 \mathrm{~cm}$ depth in autumn 2011 in the ForHot forest site.

with $8 \mathrm{~cm}$ side, made of nylon mesh and constructed according to Wallander et al. (2001). One type of bag was filled with $30 \mathrm{~g}$ quartz sand, 0.36-2.0 mm particle size, 99.6\% $\mathrm{SiO}_{2}$ (Ahlsell $\mathrm{AB}$, Sweden) heated to a temperature of $600{ }^{\circ} \mathrm{C}$ overnight to remove all organic carbon and after that acid-washed $(\mathrm{HCl} 1 \mathrm{M})$ and rinsed several times in tap water. The other type of bags were filled with the same sand mixed with $2 \%$ (dwt) maize compost. The maize compost was produced by cutting maize leaves into small pieces and composting them in an isolated plastic compost bin for 12 months. The compost was then maintained at $+4^{\circ} \mathrm{C}$. Fresh compost was forced through a $2 \mathrm{~mm}$ mesh and then mixed with dry sand to make a uniform mixture. The sand-maize mixture had a carbon content of $1.0 \%$.

One sand-only and two maize-amended meshbags were buried at the interface between the organic and mineral layer in each of the 10 plots along the four transects in May 2012. At this time, a subset of bags was frozen, for analysis at the end of the experiment, to represent the starting concentrations of ergosterol, carbon, ${ }^{13} \mathrm{C}$ and ${ }^{15} \mathrm{~N}$. The sand only bags and one of the maize-amended bags in each plot were harvested in October 2012 after 5 months of incubation. The other maize-amended bag was harvested in May 2013 after 12 months of incubation. All meshbags were visually inspected at harvest and fungal colonization was estimated according to a six grade scale (Wallander et al., 2001). The contents of the sandonly meshbags were freeze-dried, homogenized, split into two parts, and half of the material was used to estimate fungal biomass (ergosterol) and the other half for estimating the fungal community composition. The content of the maize-amended meshbags was freeze-dried and then milled in a ball mill and used for carbon and nitrogen content and isotopic measurements. Fungal biomass (ergosterol) was also measured from subsamples from the maizeamended bags from the first harvest (5 months).

\subsection{Ergosterol analysis}

Freeze-dried samples from the meshbags were analyzed for ergosterol content to provide an estimate of the EMF biomass (Wallander and Nylund, 1992). A sample of $5 \mathrm{~g}$ sand or sand-maize mixture was extracted with $5 \mathrm{ml} 10 \% \mathrm{KOH}$ in methanol. The samples were sonicated for $15 \mathrm{~min}$, extracted overnight and then refluxed at $70^{\circ} \mathrm{C}$ for $90 \mathrm{~min}$. After cooling, $1 \mathrm{ml} \mathrm{H}_{2} \mathrm{O}$ and $2 \mathrm{ml}$ cyclohexane were added. The samples were mixed in a vortex apparatus for $20 \mathrm{~s}$, centrifuged for $5 \mathrm{~min}$ at $900 \mathrm{~g}$, and the cyclohexane phase was then transferred to another test-tube. The methanol was extracted with a further $1.5 \mathrm{ml}$ cyclohexane. The cyclohexane was evaporated under $\mathrm{N}_{2}$ and the samples were dissolved in $1 \mathrm{ml}$ of methanol. Prior to the quantification of ergosterol, the samples were filtered through a $0.5 \mu \mathrm{m}$ Teflon syringe filter (Millex LCR-4, Millipore, Milford, MA, USA). A subsample of $50 \mu \mathrm{l}$ extract was injected into a chromatographic system consisting of a high-performance liquid chromatograph (Hitachi model L2130), a UV detector (Hitachi model L2400) and a C18 reversed-phase column (Elite LaChrome) preceded by a C18 reversed-phase guard column (Elite LaChrome). Extracts were eluted with methanol at a flow rate of $1 \mathrm{ml} \mathrm{min}^{-1}$, and the absorbance was measured at $282 \mathrm{~nm}$.

\subsection{DNA extraction, PCR and 454 sequencing}

DNA was extracted from 32 homogenized samples (representing the first 8 temperature points, $0-5.5^{\circ} \mathrm{C}$ warming, across the 4 transects) by adding CTAB-SDS buffer ( $2 \%$ cetrimonium bromide, $2 \%$ sodium dodecyl sulfate, $2 \mathrm{mM}$ EDTA, $150 \mathrm{mM}$ Tris- $\mathrm{HCl}, \mathrm{pH} 8$ ), vortexing, and then incubating at $65{ }^{\circ} \mathrm{C}$ for $1.5 \mathrm{~h}$, followed by chloroform addition, vortexing, supernatant removal, and isopropanol/ ethanol precipitation. The pellet was resuspended in $50 \mu \mathrm{l}$ of MilliQ-water (Millipore) and further cleaned using Wizard DNA Clean-Up kit (Promega, Madison, WI). PCR amplification of the ribosomal ITS DNA was carried out for each sample in 3 triplicate $25 \mu \mathrm{l}$ reactions using the fungal-specific primers ITS1F (Gardes and Bruns, 1993) and ITS4 (White et al., 1990). Each primer was elongated with adaptors required for 454 pyrosequencing (ITS1F-B adaptor and ITS4-A adaptor). The ITS4-A primer contained a sample specific tag consisting of 8 bases ( $5^{\prime}$-CCATCTCATCCCTGCGTGTCTCC GACTCAGXXXXXXXXTCCTCCGCTTATTGATATGC- $3^{\prime}$ ), which the ITS1 F-B adaptor lacked (5'-CCTATCCCCTGTGTGCCTTGGCAGTCTCAGCTT GGTCATTTAGAGGAAGTAA-3'). PCR products were purified with Agencourt AMPure kit (Agencourt Bioscence Corporation, Beverly, MA, USA) to remove residual salts, primers and primer dimers. The concentration of the purified PCR products was measured with the PicoGreen ds DNA Quantification Kit (Molecular Probes, Eugene, OR, USA) on a FLUOstar OPTIMA (BMG LABTECH Gmbh, Ortenberg, Germany). Equal amounts of DNA from each sample were pooled into one single pool and submitted for 454 pyrosequencing. Sequencing (starting from the ITS4 fragment end) was performed on a FLX 454 (Roche Applied Biosystems) using the Lib-L chemistry at the Pyrosequencing facility at Lund University, Lund, Sweden. The 32 samples from the sand-only meshbags comprised half of the pool submitted for sequencing on $1 / 4$ of a 454 sequencing plate.

\subsection{Bioinformatic analysis}

All bioinformatic analyses were performed using the software Mothur v1.33 (Schloss et al., 2009) and default parameters, unless otherwise stated. Sequence filtering was performed with the trim.seqs algorithm; sequences without template primers (allowing two mismatches) or MID sample barcodes (allowing one mismatch) were removed. After template primers were removed, sequences less than 175 bp long were excluded. Sequences were then trimmed to include only the ITS2 region with ITSx (BengtssonPalme et al., 2013), using the additional chimera removal tool. Sequences were clustered using the unsupervised Bayesian clustering algorithm Clustering 16S rRNA for Operational Taxonomic Unit (OTU) Prediction (CROP), with a similarity cutoff of $97 \%$ (Hao et al., 2011). Clusters containing less than 3 reads or only found in one meshbag sample (one PCR reaction) were removed. Search for sequence identities were performed by iteratively BLASTing against 3 different sequence databases: first the UNITE (Koljalg et al., 2005; http://unite.ut.ee/index.php) reference sequence database (5925 seqs, release date 2015-08-01); second the UNITE representative sequence database (16,849 seqs, release date 2015-08-01); third the full UNITE + INSD sequence database $(476,000$ seqs, release 
date 2015-08-01). Query sequences failing to match a sequence from the database were then queried against the next database, and sequences were assigned to operation taxonomic units (OTUs) when there was at least $97 \%$ similarity between query sequence and top hit, given at least $90 \%$ coverage of the query sequence length. All sequence data has been archived at the national Center for Biotechnology Information Sequence Read Archive under the Bioproject accession SUB3256455. Using names and taxonomy associated with the OTUs, the total fungal community was divided by function (ectomycorrhizal fungi, saprotrophic fungi, and ericoid/ unknown ecology fungi) based on the most current knowledge of the ecology of known close relatives (genera or species) according to Tedersoo et al. (2010). After filtering, each sample was rarified to the median number of reads (800) using the "rrarefy" function in the VEGAN package (Oksanen et al., 2013) in R (R Core Team, 2013). For community comparison (all fungi, ectomycorrhizal fungi, or saprotrophic fungi) sequence read abundances were converted to fractional abundance, such that the read abundances for all OTUs for each sample totalled to 1 .

\subsection{Isotopic analysis and calculations}

The freeze-dried, milled material from the bags containing maize compost was analyzed to determine natural abundance of carbon and nitrogen isotopes $\left(\delta^{13} \mathrm{C}, \delta^{15} \mathrm{~N}\right)$, and the amount of carbon and nitrogen. Carbon and nitrogen content (\%) was assessed by flash-combustion in a Flash 2000 elemental analyzer, and the isotopic ratios determined using a DELTA V Plus isotope-ratio mass spectrometer (IRMS) connected. The results are expressed as deviations relative to the respective international standards (Vienna Pee Dee Belemnite, V-PDB) and atmospheric $\mathrm{N}_{2}$, where:

$\delta^{13} \mathrm{C}$ or $\delta^{15} \mathrm{~N}=[($ Rsample-Rstandard $) /$ Rstandard $] \times 1000(\% 0)$

and $R$ is the molar ratio of ${ }^{13} \mathrm{C} /{ }^{12} \mathrm{C}$ or ${ }^{15} \mathrm{~N} /{ }^{14} \mathrm{~N}$. The standard deviation of ten replicate samples was $0.07 \%$ for $\delta^{13} \mathrm{C}$ and $0.16 \%$ for $\delta^{15} \mathrm{~N}$.

The proportion of $\mathrm{C} 4$ carbon was calculated using a twocomponent mixing model, and the proportion of new carbon was calculated as 1 - C4 carbon.

$$
\text { C4carbon }=\frac{\delta 13 \text { Csample }-\delta 13 \text { CNewcarbon }}{\delta 13 C C 4-\delta 13 \text { CNewcarbon }}
$$

The value used for $\delta^{13} \mathrm{CC} 4$ was either $-13.4 \%$ (original maize compost) or the values from the meshbags collected from the hottest plots (plot 9-10) where the trees were dead and no EMF was produced. These values were $-13.8 \%$ after 5 months and $-14.2 \%$ after 12 months of incubation. Using these values, we may exclude import due to saprotrophic fungi and dissolved organic matter in our estimates of carbon sequestration by EMF. The value used for $\delta^{13} \mathrm{CNew}$ carbon was $-26.8 \%$ and was based on extracted mycelia from meshbags with sand from a study of Swedish Norway spruce forests $(-26.8 \% 0 \pm 0.06$, mean $\pm S E, n=3$; Wallander et al., 2011).

\subsection{Statistical analysis}

All statistical analyses were performed using the VEGAN package (Oksanen et al., 2013) in R ( $\mathrm{R}$ Core Team, 2013). One-way ANOVAs were performed to examine the effect of warming on fungal growth and carbon and nitrogen content and isotopic signatures in meshbags, as well as the relationship between warming and the abundance of fungal functional groups and the most abundant fungal taxa. Fungal communities were visualized with ordination using non-parametric multidimensional scaling (NMDS) using the metaMDS function. All ordinations were conducted in 2 dimensions. Relationships between community composition and either transect or soil warming were examined for significance with permutational multivariate analysis of variance (PERMANOVA; Anderson, 2001; calculated using the VEGDIST function with Bray-Curtis dissimilarity). PERMANOVA analyses were conducted for the total community (all fungal OTUs), as well as the ectomycorrhizal and saprotrophic communities, separately. For all statistical tests, degrees warmed (plot soil temp - control plot temperature measured when harvesting the 5 month incubation; October 2012) was used as the temperature data; for graphical depictions of fungal community effects across the warming gradient relative abundances were averaged across the four subplots of a point along the transects and displayed with the average temperature for those 4 plots $(n=4$, for each level of warming treatment).

\section{Results}

The temperatures in the first 8 plots along the gradients varied between 0 and $5.5^{\circ} \mathrm{C}$ above unwarmed controls (Table 1 ). In the two last plots, temperatures increased much more to between $9{ }^{\circ} \mathrm{C}$ and $53^{\circ} \mathrm{C}$ above ambient and in these plots the trees died. Six maize-amended meshbags but no sand only meshbags were retrieved from the plots with the two highest temperatures. All bags were retrieved from plots $1-8$.

\subsection{Effects of temperature on fungal growth}

After 5 months of incubation in the soil at up to $5.5^{\circ} \mathrm{C}$ warming, there was no relationship between ergosterol content of sand only meshbags and degrees warmed (Fig. 2), but ergosterol content of maize-amended meshbags exhibited a decreasing trend with increasing temperature at $\mathrm{p}<0.06(\mathrm{~F}=3.95$; Fig. 3). Ergosterol concentrations increased from on average $1.0 \pm 0.2 \mu \mathrm{g} \mathrm{g}^{-1}$ in maizeamended meshbags not incubated in the soil to on average

Table 1

Measured temperatures at $5 \mathrm{~cm}$ soil depth across the four transects spanning the warming gradient used in this study.

\begin{tabular}{|c|c|c|c|}
\hline Plot position along warming gradient ${ }^{\mathrm{a}}$ & Temperature Range (above background) & Mean Temp. (above background) & St. Err. \\
\hline 1 & $0.05-0.96$ & 0.45 & 0.19 \\
\hline 2 & $-0.19-2.02$ & 1.04 & 0.48 \\
\hline 3 & $1.74-2.26$ & 1.88 & 0.12 \\
\hline 4 & $2.36-2.5$ & 2.40 & 0.05 \\
\hline 5 & $2.44-3.14$ & 2.89 & 0.16 \\
\hline 6 & $3.12-4.08$ & 3.70 & 0.20 \\
\hline 7 & $3.68-3.96$ & 3.82 & 0.06 \\
\hline 8 & $4.6-5.54$ & 5.02 & 0.20 \\
\hline 9 & $9.3-21.3$ & 17.49 & 2.78 \\
\hline 10 & $34.14-52.94$ & 42.37 & 4.06 \\
\hline
\end{tabular}

a Each mean and standard error correspond to 4 subplots. Only positions $1-8$ were used for fungal community composition. 


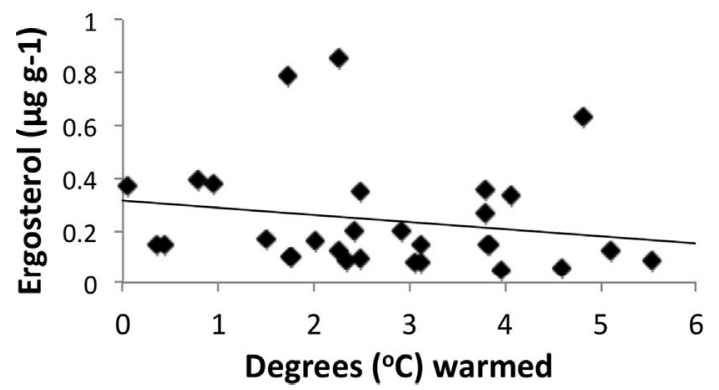

Fig. 2. Fungal biomass (ergosterol) vs. degrees warmed (above background controls) in the sand-filled meshbags after 5 months of incubation in the soil. Each point represents the erogosterol content of one meshbag, and the X-axis corresponds to the degrees of soil warming of that plot.

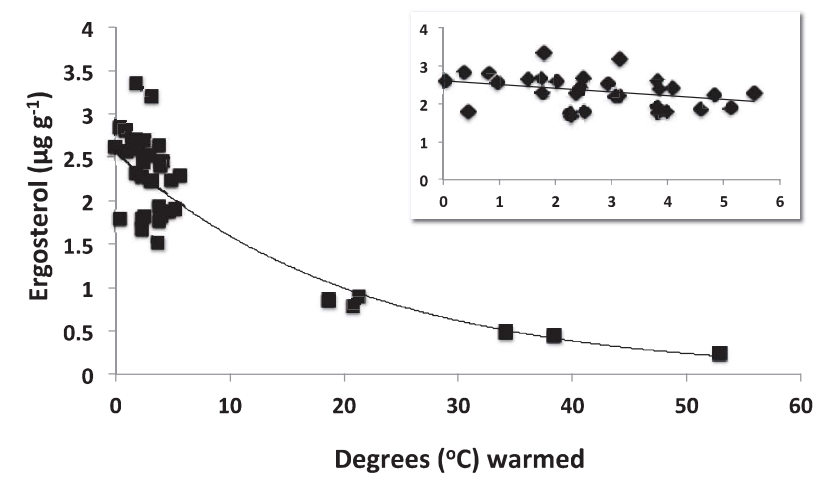

Fig. 3. Fungal biomass (ergosterol) vs. degrees warmed (above background controls) in the maize-amended meshbags after 5 months of incubation in the soil. Each point represents the erogosterol content of one meshbag, and the X-axis corresponds to the degrees of soil warming of that plot. Inset depicts the effect of elevated temperature up to $5.5^{\circ} \mathrm{C}$ above ambient.

$2.0 \pm 0.1 \mu \mathrm{g} \mathrm{g}^{-1}$. Values in maize-amended meshbags were considerably higher than values from sand only meshbags $\left(0.24 \pm 0.04 \mu \mathrm{g} \mathrm{g}^{-1}\right.$ ). Where warming was greater than $5.5^{\circ} \mathrm{C}$ (plot 9-10) ergosterol content in the maize-amended meshbags declined with temperature and values were lower than in the original maize-amended meshbags before incubation (Fig. 3). Visual assessment of hyphal density in the sand only meshbags and maize-amended meshbags (up to $5.5^{\circ} \mathrm{C}$ above ambient) after 5 months indicated no difference in hyphal abundance along the temperature gradient, but visual hyphal biomass scores in the maize-amended meshbags incubated for 12 months exhibited a significant negative relationship to degrees warmed $(\mathrm{p}<0.003$, $\mathrm{F}=11.03$ ). Visually assessed hyphal biomass (averaged across all temperatures) from the maize-amended meshbags did not change significantly between $5(4.0 \pm 0.14)$ and 12 months $(3.9 \pm 0.13)$ of incubation, but was significantly higher $(\mathrm{t}=2.52, \mathrm{p}<0.015)$ than visually assessed hyphal density in the sand only meshbags $(3.4 \pm 0.14)$.

\subsection{Effects of temperature on composition of the fungal community}

Following quality filtering and clustering there were 29,555 sequence reads. Following rarefaction to 800 sequence reads per sample there were 22,404 sequence reads belonging to 114 OTUs; 20,81 , and 13 of ectomycorrhizal, saprotrophic, and ericoid/unknown trophic mode, respectively. 11 of the 13 OTUs of ericoid/ unknown trophic mode were Helotiales, and two were Oidiodendron. Sand only meshbags were mainly colonized by ectomycorrhizal fungi, which contributed $44-97 \%$ of the sequences from each

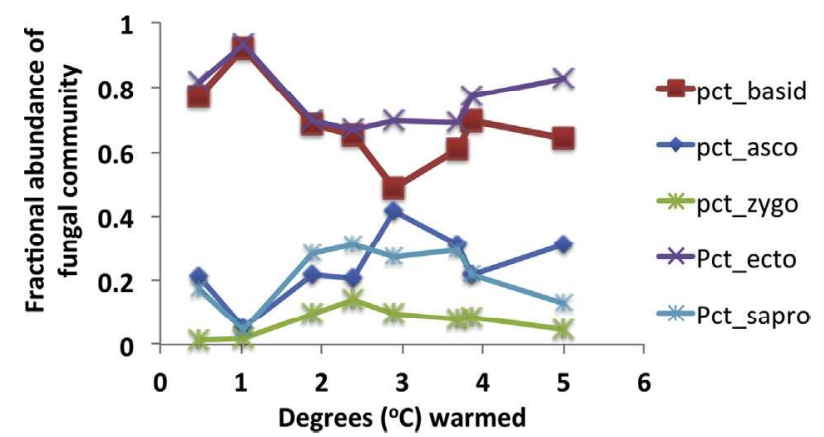

Fig. 4. Respective fractions of ectomycorrhizal, saprotrophic and ericoid fungal sequence reads in the sand-filled meshbags along the temperature gradient. Each point represents the mean of four meshbags from each of the four transects, and temperature values along the $\mathrm{X}$-axis represent the increase of mean measured soil temperature across the four subplots compared to background control.

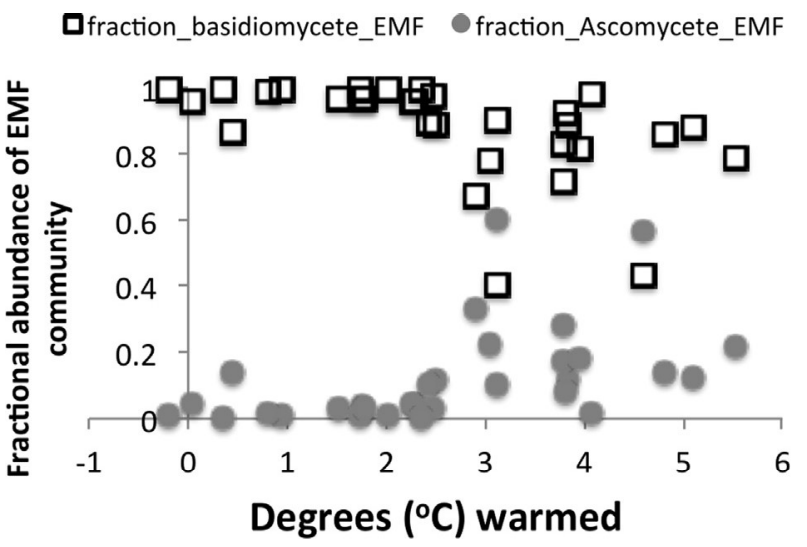

Fig. 5. Proportion of ectomycorrhizal sequence reads belonging to either ascomycetes or basidiomycetes.

meshbag. Across all 32 sand only meshbags, an average of $76 \%$ of sequence reads were of known EMF origin, 22\% from saprotrophic fungi, and $2.1 \%$ from ericoid fungi or fungi of unknown trophic mode (Fig. 4). Amongst the ectomycorrhizal fungi, $12 \%$ of sequence reads were from ascomycetes and $88 \%$ were from basidiomycetes. The relative abundance of ectomycorrhizal, saprotrophic, and ericoid/unknown fungal sequences was not affected by warming, though the abundance of ascomycetes increased at $\mathrm{p}<0.064$ $(\mathrm{F}=3.72)$, and the abundance of basidiomycetes decreased at $\mathrm{p}<0.057(\mathrm{~F}=3.93)$. Warming was also associated with a significant increase in the ascomycetous fraction of ectomycorrhizal sequence reads (mean $12 \%$; range $2-30 \%$; $\mathrm{p}<0.01, \mathrm{~F}=9.03$ ) and corresponding decrease in the basidiomycetous fraction $(p<0.01$, $\mathrm{F}=$ 9.03; Fig. 5).

Elevated temperatures did not significantly influence the composition of either the total fungal community nor the EMF community (Fig. 6A), while the saprotrophic fungal community in meshbags was significantly affected by soil warming (Fig. 6B; $\mathrm{R}^{2}=0.062, \mathrm{p}<0.02$ ). Neither the total fungal community, nor that of saprotrophic or ectomycorrhizal fungi were significantly associated with soil transect. By far the most abundant fungal taxa was the ectomycorrhizal fungus Amphinema; $43 \%$ of all sequence reads belonged to Amphinema byssoides and 56\% to Amphinema sp. Neither Amphinema sp. nor A. byssoides abundance was affected by warming. Amongst the 24 fungal taxa that each constituted more than $0.5 \%$ of all sequence reads (and constituted in total $89 \%$ of all sequence reads), ectomycorrhizal Wilcoxina rehmii $(\mathrm{p}<0.042$, $\mathrm{F}=4.55$ ) and the saprotrophic Thysanophora penicillioides 


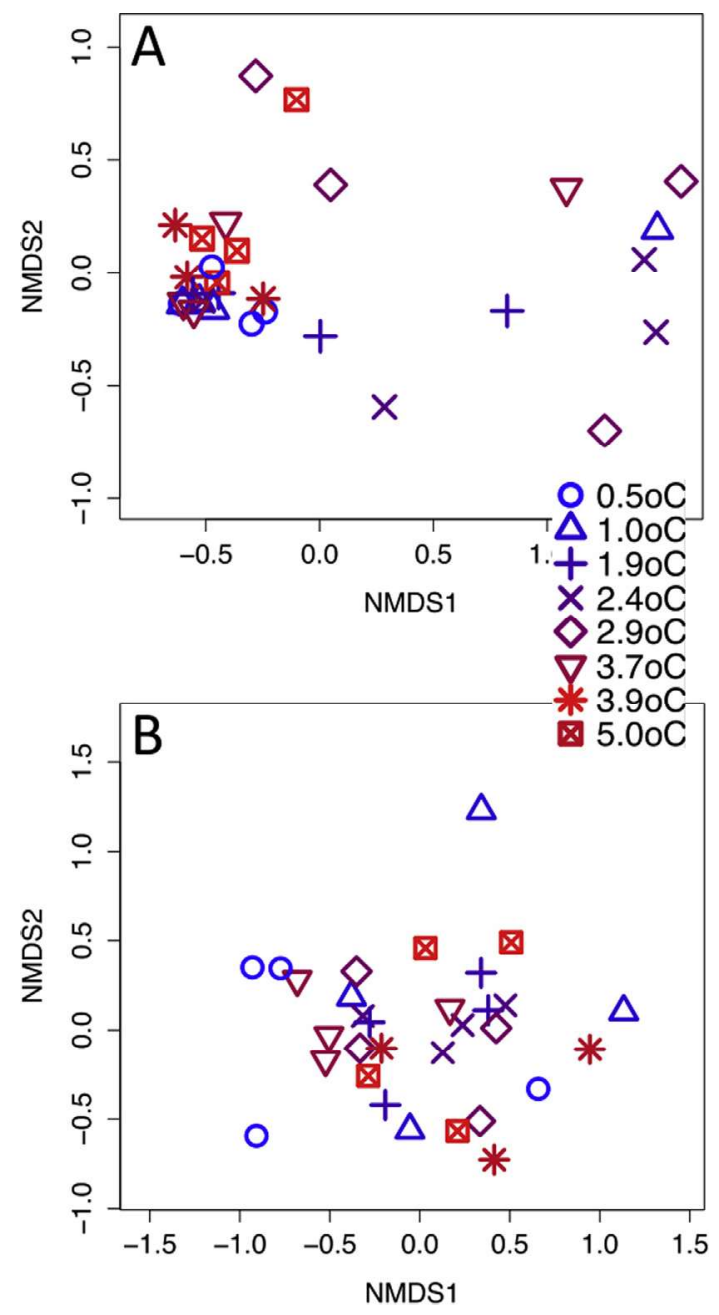

Fig. 6. Effect of temperature on the (A) ectomycorrhizal community ( $76 \%$ of all sequence reads; stress $=0.08)$ and $(B)$ saprotrophic fungal community $(\sim 22 \%$ of all sequence reads; stress $=0.12$ )

( $\mathrm{p}<0.035, \mathrm{~F}=4.93$ ) were positively associated with soil warming, and the saprotrophic Dothideomycetes sp. 1 was negatively associated with soil warming $(\mathrm{p}<0.045, \mathrm{~F}=4.43$; Fig. 7$)$. The combined abundance of the two Wilcoxina OTUs and the closely related Trichophaea hybrida increased significantly in response to warming, both as a fraction of the total fungal community $(\mathrm{p}<0.019, \mathrm{~F}=6.2)$ and as a fraction of the ectomycorrhizal abundance $(\mathrm{p}<0.016$, $\mathrm{F}=6.6$ ).

\subsection{Fungal carbon sequestration}

Neither the carbon and nitrogen content nor the $\delta^{13} \mathrm{C}$ or $\delta^{15} \mathrm{~N}$ of the maize-amended bags were significantly associated with soil warming in either the 5 months or the 12 months incubations up to $5.5^{\circ} \mathrm{C}$ above ambient. The carbon content of maize-amended meshbags was not significantly different from the amount present before incubation in the soil and did not change significantly from the 5 months incubation to the 12 months incubation. The carbon isotopic composition, on the other hand, decreased significantly between the 5 months incubation and the 12 months incubation $(\mathrm{p}<0.002, \mathrm{~F}=11.28) ; \delta^{13} \mathrm{C}$ of the carbon in the maize bags decreased from $-13.4 \pm 0.08$ before incubation, to $-14.2 \pm 0.05$ after 5 months and $-14.7 \pm 0.1$ after 12 months (Fig. 8). However, carbon isotopic composition also changed in the two last positions along each transects with the highest temperatures $\left(9{ }^{\circ} \mathrm{C}\right.$ to $50^{\circ} \mathrm{C}$ above ambient) where no EMF growth was observed. Values on average were $-13.8 \pm 0.2$ at the first harvest ( 5 months) and $-14.2 \pm 0.1$ at the second harvest (12 months) in these plots. The proportion of new carbon (originating from EMF) in the meshbags at harvest was estimated for the temperature range $0-5.5^{\circ} \mathrm{C}$ above ambient using the mixing model described above. Two values were used for $\delta^{13} \mathrm{C}-\mathrm{C} 4$ in the model: (1) the $\delta^{13} \mathrm{C}$ composition of the original maize compost assuming that all carbon that has entered the meshbags after incubation originates from EMF fungi; (2) the average $\delta^{13} \mathrm{C}$ composition of the meshbags in the two hottest plots where the trees were dead and no EMF carbon was produced. The change in ${ }^{13} \mathrm{C}$ composition of these bags could be an effect of dissolved organic matter entering the bag, or colonization by saprotrophic fungi that bring in carbon from outside. Over the first $5.5{ }^{\circ} \mathrm{C}$ of warming no effect of warming on ectomycorhhizal carbon inputs into meshbags was found. On average $0.42 \pm 0.04 \mathrm{mg} C$ per gram meshbag contents (sand + compost) was of EMF origin after 5 months, and $0.7 \pm 1 \mathrm{mg} \mathrm{C}$ per gram sand + compost after 12 months of incubation using -13.4 (the original maize compost) as the $\delta^{13} \mathrm{C}$-C4. If we scale up the $\mathrm{C}$ sequestration in the meshbags and assume that the production in the meshbags resembles the mycelial production in the uppermost $10 \mathrm{~cm}$ of the soil, an average production of $650 \pm 60 \mathrm{kgC}$ per hectare of EMF origin was estimated at the first harvest (5 months), and $1030 \pm 170 \mathrm{~kg} \mathrm{C} \mathrm{ha}^{-1}$ was estimated at the second harvest (12 months). If we instead use the values from the most heated plots as the $\delta^{13} \mathrm{C}-\mathrm{C} 4$ the corresponding values were $360 \pm 50 \mathrm{~kg} \mathrm{C} \mathrm{ha}^{-1}$ after 5 months and $560 \pm 170 \mathrm{~kg} \mathrm{Cha}^{-1}$ after 12 months. The proportion of carbon in the maize-amended bags originating from EMF increased significantly during the incubation period from $6.0 \%$ after 5 months incubation to $8.2 \%$ after 12 months of incubation $(\mathrm{F}=4.63, \mathrm{p}<0.036)$ based on changes in the carbon isotopic composition.

\section{Discussion}

\subsection{Spruce responses}

Measurements performed in 2013 ( 1 y after our study, assessing growth from 2012 to 2013) indicate significantly greater stem growth of dominant Sitka spruce trees with warming up to $2.7^{\circ} \mathrm{C}$ (average across 12 plots and 4 transects; average warming of 1,1.9, and $2.7^{\circ} \mathrm{C}$ ) and significantly reduced stem growth with warming at $5.8^{\circ} \mathrm{C}$ (average across 4 plots and 4 transects; no plots were sampled between 2.7 and $5.8^{\circ} \mathrm{C}$ warming; Sigurdsson et al., 2014; Sigurdsson et al., 2016). Measurements of stand basal area increment from 2013 to 2016 observed increased growth at 1 and $1.9^{\circ} \mathrm{C}$ warming but moderately reduced growth at $2.7^{\circ} \mathrm{C}$ and severely reduced growth at $5.8^{\circ} \mathrm{C}$ warming (unpublished data). At the time of our sampling there was no observable increase in mortality across the warming gradient, but in 2017 ( 5 years later), there was moderately increased stem mortality at $2.7^{\circ} \mathrm{C}$ warming $(\sim 20 \%$ of basal area) and significantly increased mortality ( $50 \%$ of basal area) at $5.8^{\circ} \mathrm{C}$ warming (unpublished data); at $17.5^{\circ} \mathrm{C}$ warming, all trees had died (no plots were sampled between 5.8 and $17.5^{\circ} \mathrm{C}$ warming).

\subsection{Ectomycorrhizal growth}

In contrast to what we expected, we did not observe any warming-associated increase in EMF mycelial growth up to $5.5^{\circ} \mathrm{C}$ warming; we observed some indication of a decreasing trend, particularly above $4{ }^{\circ} \mathrm{C}$ warming. EMF production was sharply reduced at greater than $9{ }^{\circ} \mathrm{C}$ warming, where we observed $100 \%$ 


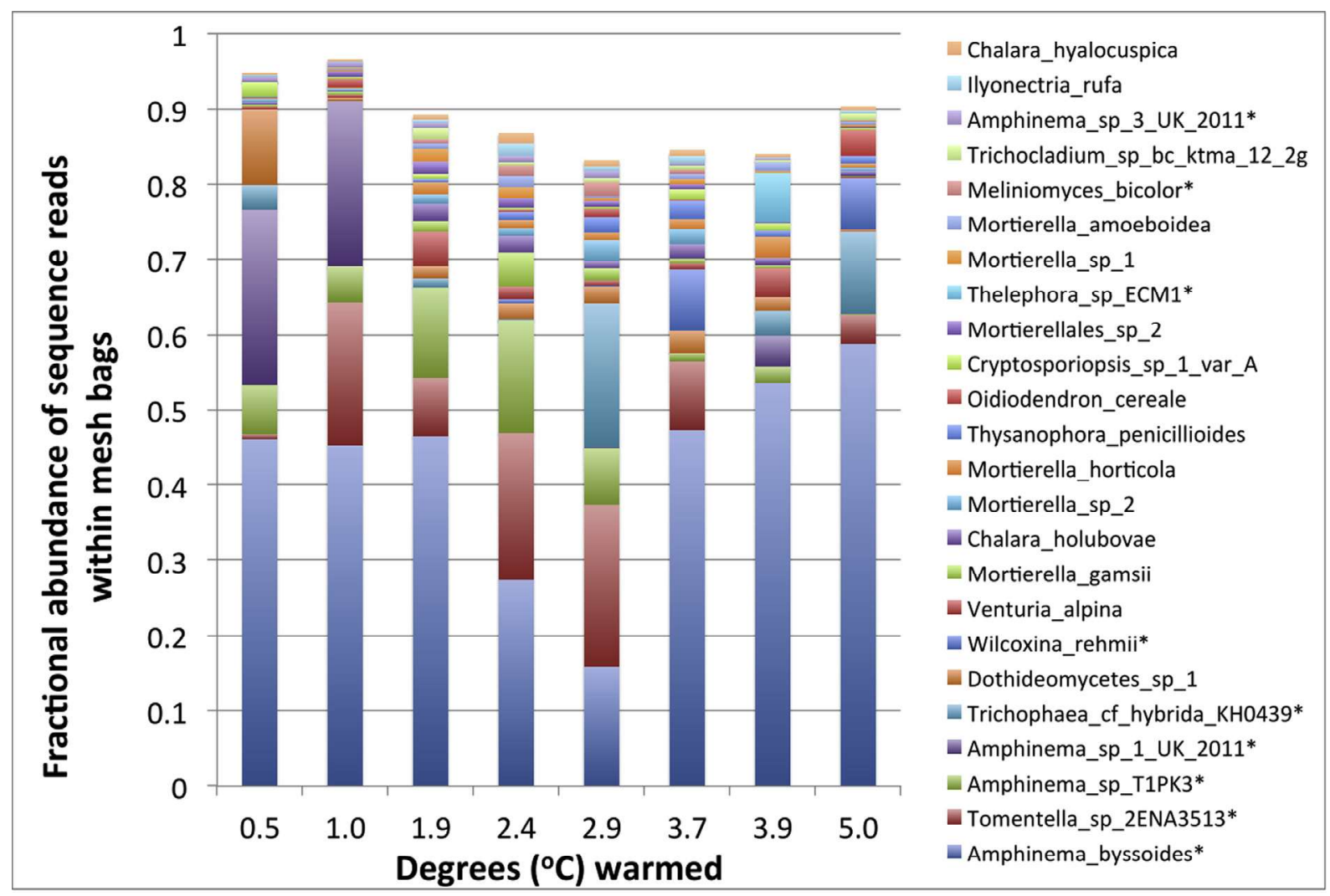

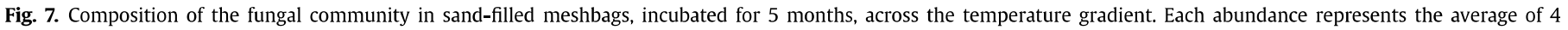

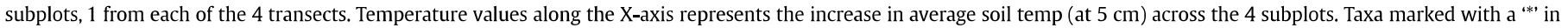
the legend are identified as ectomycorrhizal.

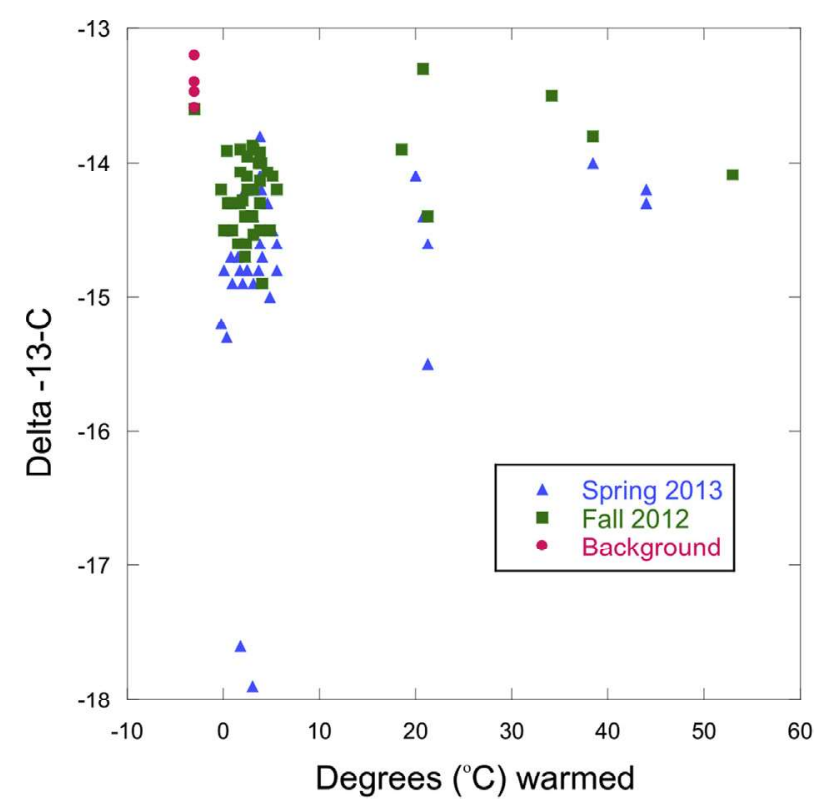

Fig. 8. Effects of elevated temperature (Degrees $\left({ }^{\circ} \mathrm{C}\right.$ ) warmed) on carbon isotopic composition of meshbags amended with maize compost after 5 and 12 months incubation in the soil. Data from all four transects are included in the graph.

stem mortality at the time of sampling.

Multiple studies have noted increased EMF abundance with warming when increases in above or belowground tree growth were also observed (Jarvis and Linder, 2000; Strömgren and Linder, 2002; Clemmensen et al., 2006; Leppälammi-Kujansuu et al., 2013; Yin et al., 2013; Qiao et al., 2016). However, the responses of EMF biomass and growth to warming do not always follow changes in plant performance; Li et al. (2015) found reduced EMF colonization and fungal biomass in Picea asperata stands after soil warming with open top chambers, despite elevated fine root biomass and aboveground plant growth, and Deslippe et al. (2011) found no increase in root biomass or ectomycorrhizal colonization despite a $55 \%$ increase in aboveground Betula nana biomass in a closed-topchamber experiment, which is a similar response as was found in our study. Our results indicate that increases in aboveground growth may not be paired with increases in belowground carbon flows to EMF. If warming has increased nutrient availability, this might explain increased aboveground growth and a slight decrease in belowground allocation. Indeed, while nitrogen availability measurements, made at our study sites with PRS probes in summer (2013), indicated no increase in solution $\mathrm{NH}_{4}^{+}$across $5.8^{\circ} \mathrm{C}$ of warming, they also indicated a moderate, but not significant, increase in $\mathrm{NO}_{3}^{-}$availability at $1.1^{\circ} \mathrm{C}$ and $1.9^{\circ} \mathrm{C}$ warming, a doubling of $\mathrm{NO}_{3}^{-}$availability at $2.7^{\circ} \mathrm{C}$ and a tremendous increase in $\mathrm{NO}_{3}^{-}(80-$ fold) at $5.8^{\circ} \mathrm{C}$ warming (Sigurdsson et al., 2014).

In addition to changes in plant productivity and belowground carbon allocation, EMF may be affected by warming via effects on soil moisture, which is often reduced after warming treatments (Hyvönen et al., 2007). The possibly confounding effect of drying was likely not relevant in our study since the geothermal warming of the soil did not influence soil moisture (Sigurdsson et al., 2016). The high ( $>1400 \mathrm{~mm}$ ) annual rainfall, as well as its relatively even annual distribution, may have prevented the soil moisture effects 
commonly observed with soil warming treatments.

\subsection{Fungal community composition}

In contrast to our expectations, we did not detect a significant influence of soil warming on total fungal community composition or EMF community composition in the meshbags. We did, however, observe a significant influence of soil warming on saprotrophic fungal community composition and increased abundance of ascomycetous EMF and total ascomycete abundance with soil warming. The relative abundance of ascomycete EMF increased from an average of $\sim 3 \%$ of total EMF abundance below $2{ }^{\circ} \mathrm{C}$ warming to an average of $\sim 20 \%$ above $3.5^{\circ} \mathrm{C}$ warming; the only single EMF OTU that responded significantly to warming was the ascomycete Wilcoxina rehmii, which responded positively to warming, and the total abundance of the two Wilcoxina OTUs and Trichophaea hybrida increased significantly in response to warming. These shifts all exhibited a distinct beginning above $2.5^{\circ} \mathrm{C}$ warming in our study, the point above which recent (2017, $5 \mathrm{y}$ after the current study) surveys along this gradient have observed increased tree mortality.

As with ectomycorrhizal abundance, whether warming has a significant effect on fungal community composition varies between studies, but effects are commonly linked to moisture responses. Deslippe et al. (2011) found that warming had a significant effect on the fungal community on B. nana roots, while Fujimura et al. (2008) found no warming effect on Salix roots. Both Allison and Treseder (2008) and Treseder et al. (2016) found significant effects on the soil EMF community in an Alaskan closed-top-chamber study, in both of which warming also caused a significant decrease in soil moisture. Geml et al. (2015), who found a significant effect of warming on soil fungal communities, and Peltoniemi et al. (2015), who did not, both found significant interactive effects between warming and soil moisture on fungal community composition. Reported phylogenetic responses to warming have also varied. While Deslippe et al. (2011) observed increased abundance of Cortinariaceae species and decreased abundance of Russulaceae species in response to warming, Deslippe et al. (2012) found warming increased the abundance of Russulales and Helotiales. Geml et al. (2015) noted increases in ericoid mycorrhizal fungi, ascomycete EMF and soil zygomycetes in response to warming and a decrease in the relative dominance of basidiomycete EMF. Allison and Treseder (2008) observed an increase in relative abundance of ascomycetes, and Treseder et al. (2016) observed that warming increased the relative dominance of saprotrophic filamentous fungi and ectomycorrhizal fungi, but decreased the abundance of basidomycete yeasts. Treseder et al. (2016) also observed a significant increase in pezizalean fungi after warming, but Wilcoxina and Trichophaea were not amongst the taxa. Among these varied responses an increase in the abundance of ascomycetes and ascomycetous EMF has been observed in multiple studies, as it was in ours.

Pezizalean OTUs from the pyronemataceous genera Wilcoxina and Trichophaea constituted $75 \%$ of all ascomycetous ectomycorrhizal sequences in our study and accounted for all of the warming increase in ascomycetous EMF. SSU-based alignments have placed T. hybrida and Wilcoxina as sister genera on a single branch of phylogenetic trees (Landvik et al., 1997; Fujimura et al., 2005) and both Wilcoxina OTUs (W. rehmi and W. sp. 1) and both Trichophaea OTUs (T. hybrida var A. and T. hybrida var B.) exhibited, individually, increasing abundance with soil warming, particularly above $2.5^{\circ} \mathrm{C}$. Wilcoxina EMF have a global distribution and form ectomycorrhizal associations with many plant species, including both gymnosperms and angiosperms, and commonly form ectendomycorrhizas with Larix and Pinus hosts (Yu et al., 2001), which may indicate an elevated potential for necrotrophy. Their prevalence on nursery grown seedlings and dominance in early colonization of seedlings after fire or clear cut logging (Jones et al., 2010) has been suggested to arise from a potentially high ability for facultative saprotrophy (Yu et al., 2001). Studies comparing the benefits of mycorrhizal association between different EMF (basidiomycetes and ascomycetes and non-mycorrhizal) have found Wilcoxina taxa to rank high in terms of seedling biomass (Siemens and Zwiazek, 2008) and nitrogen uptake (Jones et al., 2009). Warmer soil temperatures may directly favor the growth of Wilcoxina and Trichophaea. Indeed, Wilcoxina is commonly identified after fire (Fujimura et al., 2005; Jones et al., 2010), and Šimonovičová et al. (2014) found Trichophaea abundans to be heat tolerant. It is also possible that above $2.5^{\circ} \mathrm{C}$ there was higher root turnover or mortality or reduced root fitness, which is partly supported by observations of elevated tree mortality $5 \mathrm{y}$ later, and the increased relative abundance of Wilcoxina and Trichophaea may thus be a reflection of their facultative necrotrophy on dead fine roots. Alternatively, increased abundance of Wilcoxina, Trichophaea, and other ascomycetous EMF in comparison to basidiomycetes may result from lower belowground carbon allocation by host plants and more aggressive colonization potential or higher saprotrophic abilities of these EMF. Further work examining fine root density and turnover responses to warming may help illuminate what is driving the increased relative abundance of Wilcoxina and Trichophaea. In addition, given that multiple studies have observed increases in ascomycetous EMF with warming, a deeper understanding of the ecological niches of these distinct lineages of EMF is called for. If ascomycotan and basidiomycotan EMF have significantly different mutualistic abilities then such a species shift may have important repercussions for forest productivity, and if ascomycotan and basidiomycotan fungal necromass vary in their recalcitrance the increases in ascomycete abundance we observed could have a significant impact on soil carbon sequestration.

We observed a significant shift in saprotrophic community composition with soil warming, and two ascomycete taxa exhibited a significant response to warming. Thysanophora penicillioides is a widely distributed, common, necrotrophic saprotroph found to grow internally in needles from a range of gymnosperms shortly after litterfall and sporulate through the stomata (Kendrick, 1961; van Maanen and Gourbiere, 1997). The increased abundance of Th. penicillioides may indicate a competitive advantage over other saprotrophic fungi with warming or an increase in needle litter fall. Despite its reported obligate necrotrophy on fresh litter material on the soil surface, its abundance in the buried sand only meshbags ( $1 \%$ of fungal reads, $4.6 \%$ of saprotrophic fungal reads) is not unusual; it has been found in simliar buried sand only ingrowth meshbags in coniferous forests of the Czech Republic (Rosenstock et al., 2016) and Sweden (Nicolas et al., 2017) and beech forests in Switzerland (de Witte et al., 2017). It is possible some portion of the sequence reads derive from downward percolation of spores into the meshbags. Sequences from the Dothideomycetes sp. 1 OTU did not form a close match with anything other than unidentified environmental sequences from studies of Swedish boreal forest roots and soil; but comprised a major portion of the saprotrophic fungal reads ( $2.7 \%$ of fungal reads, $12 \%$ of saprotrophic fungal reads) and was negatively associated with soil warming.

\subsection{Warming effects on fungal contribution to soil carbon sequestration}

We endeavored to determine whether warming altered the fungal contribution to soil carbon cycling. We did not find a warming effect on the $\delta^{13} \mathrm{C}, \delta^{15} \mathrm{~N}$, or $\%$ carbon of the maizeamended meshbags in either the 5 or 12 month incubations, though we observed a significant decrease in both $\delta^{15} \mathrm{~N}$ and $\delta^{13} \mathrm{C}$ 
between the 5 and 12 month incubations and a progressive build up of ectomycorrhizal derived carbon. The mycelial biomass and necromass accumulation estimates derived from our results (300 and $500 \mathrm{~kg} C$ of EMF origin ha ${ }^{-1}$ depending on what values are used as $\delta 13 C-C 4$ in the mixing model, see above) after 5 months are similar to values found in studies from southern and central Sweden (100-600 $\mathrm{kg} \mathrm{Cha}^{-1}$, Wallander et al., 2011). EMF biomass can turnover 10 times a year (Ekblad et al., 2016; Hendricks et al., 2016), and decomposition of dead EMF mycelia is usually very slow (Schweigert et al., 2015; Ekblad et al., 2016), which indicates a large contribution to soil organic matter accumulation, though our results do not indicate that this contribution is likely to change with warming. We did not see a significant increase or decrease in EMF taxa identified with high ability to degrade recalcitrant organic matter or with high melanin content. The shifts in saprotrophic community composition we observed appear to be a direct response to warming, but we are limited in our ability to draw conclusions about the functional significance of the observed community compositional shifts. Spectroscopic examination of the soil carbon may illuminate what, if any, functional significance the observed shifts in fungal community composition may have for soil carbon cycling, and substrate addition and labeling approaches like that employed by Treseder et al. (2016), should shed further light on the phylogenetic associations between fungal community composition and changes in soil carbon cycling.

\subsection{Relevance to other systems}

Avoiding the aforementioned treatment artifacts that afflict many warming studies and consisting of a gradual warming gradient over tens of meters, the ForHot site utilized in this study represents an ideal system in many respects for studying the effects of a gradually warming climate. The lack of a warming $X$ soil moisture interaction allows the examination of warming alone, but may also limit the relevance of these results to drier ecosystems where warming may be associated with more significant moisture deficits to ecosystem productivity (Luo, 2007). The forest utilized in this study is a Sitka spruce plantation on an island with little remaining naturally occurring forest. The lack of nearby forest, the non-native host trees, and the recent lack of forest on Iceland appear to have contributed to a species poor inoculum for the ectomycorrhizal obligate Sitka spruce, as 20 ectomycorrhial OTUs is considerably lower diversity than has been reported in other meshbags studies conducted in Norway spruce forests using such deep sequencing methods (Rosenstock et al., 2016; Nicolas et al., 2017; Almeida et al., 2018). It is possible that a more diverse EMF community might have been more sensitive to soil warming. However, as noted above, total mycelial growth was similar to that observed in other fast-growing northern spruce forests (Ekblad et al., 2013).

The use of ingrowth meshbags to sample EMF community composition may also give a different picture of the community than direct extraction of DNA from soil or sampling from root tips. The meshbag sampling approach is designed to bias against saprotrophic fungi, and the same qualities that exclude saprotrophic fungi (little or no organic matter over a distance which is large for soil microbes to cross) will likely bias our sampling against some EMF taxa and in favor of others. In particular, mycorrhizal fungi of the contact exploration type, such as Russula and Lactarius, which do not produce abundant extramatrical hyphae and dominate many mature forests, are less likely to colonize meshbags, and, indeed, our data set did not contain these genera. Hagenbo et al. (2018), in a study across a Pinus sylvestris forest age gradient, also found a clear difference between the EMF community observed by meshbag sampling and that observed from extraction of DNA from soil; Russula and Cortinarius were underrepresented in the meshbag sampled community. However, they also observed that in younger forests (under $60 \mathrm{y}$; present study $<50 \mathrm{y}$ ) and over longer incubations (more than 90 days; present study $>150$ days) the EMF community pictures obtained from meshbag sampling and direct soil sampling were more comparable. Almeida et al. (2018), in a study of fertilization effects on a 45-y-old $P$. abies forest, did find differences between the EMF communities obtained by meshbag and soil sampling, but did not find a significant difference in the proportion of Russula or Cortinarius sequences, nor in the composition of exploration types between the sampling methods.

In conclusion, despite increases in tree growth at moderate warming, warming had no effect or a slight reducing effect on fungal mycelial growth, no effect on fungal carbon sequestration and limited effects on ectomycorrhizal community composition. Large increases in nutrient availability may explain the decoupling of aboveground production from belowground carbon allocation. These findings should be taken into account and further study performed to examine how belowground allocation to EMF as a fraction of primary productivity may change with warming, particularly given the predominance of ectomycorrhizal necromass in stable soil organic matter. Despite limited effects of warming on fungal community composition, increased abundance of pyronemataceous EMF and shifts in saprotrophic community composition may presage changes in mycorrhizal functioning and microbial necromass recalcitrance and degradative capacity. Further study on fine root dynamics may shed light on the functional significance of and driving forces behind the increased abundance of pyronemataceous EMF. Increasing our understanding of how the stability and turnover rate of soil carbon pools will be affected by warming, requires microbial activity measurements across a variety of warming studies, and a deeper understanding of how composition shifts in fungal communities affects the production and recalcitrance of soil organic matter.

\section{Acknowledgement}

This research was supported by a grant from the Swedish Research Council for Environment, Agricultural Sciences and Spatial Planning (nr: 239-2013-1113 for H. Wallander).

\section{References}

Allison, S.D., Treseder, K.K., 2008. Warming and drying suppress microbial activity and carbon cycling in boreal forest soils. Global Change Biol. 14, 2898-2909.

Almeida, J.P., Rosenstock, N.P., Forsmark, B., Bergh, J., Wallander, H., 2018. Ectomycorrhizal community composition and function in a spruce forest transitioning between nitrogen and phosphorus limitation. Fungal Ecol. https://doi.org/ 10.1016/j.funeco.2018.05.008.

Anderson, M.J., 2001. A new method for non-parametric multivariate analysis of variance. Austral Ecol. 26, 32-46.

Bengtsson-Palme, J., Veldre, V., Ryberg, M., Hartmann, M., Branco, S., Wang, Z. Godhe, A., Bertrand, Y., De Wit, P., Sanchez, M., et al., 2013. ITSx: improved software detection and extraction of ITS1 and ITS2 from ribosomal ITS sequences of fungi and other eukaryotes for use in environmental sequencing. Methods in Ecol. Evol. 4, 914-919.

Bruns, T., 1995. Thoughts on the processes that maintain local species diversity of ectomycorrhizal fungi. Plant Soil 170, 63-73.

Cairney, J.W.G., 2012. Extramatrical mycelia of ectomycorrhizal fungi as moderators of carbon dynamics in forest soil. Soil Biol. Biochem. 47, 198-208.

Clemmensen, KE., Michelsen, A., Jonasson, S. Shaver, G.R., 2006. Increased ectomycorrhizal fungal abundance after long-term fertilization and warming of two arctic tundra ecosystems. New Phytol. 171, 391-404.

Clemmensen, K.E., Bahr, A., Ovaskainen, O., Dahlberg, A., Ekblad, A., Wallander, $\mathrm{H}_{\text {, }}$ Stenlid, J., Finlay, R.D., Wardle, D.A., Lindahl, B.D., 2013. Roots and associated fungi drive long-term carbon sequestration in boreal forest. Science 339, 1615-1618.

Clemmensen, K.E., Finlay, R.D., Dahlberg, A., Stenlid, J., Wardle, D.A., Lindahl, B.D., 2015. Carbon sequestration is related to mycorrhizal fungal community shifts during long-term succession in boreal forests. New Phytol. 205, 1525-1536.

Davidson, E.A., Janssens, I.A., 2006. Temperature sensitivity of soil carbon 
decomposition and feedbacks to climate change. Nature 440, 165-173.

Deslippe, J.R., Hartmann, M., Mohn, W.W., Simard, S.W., 2011. Long-term experimental manipulation of climate alters the ectomycorrhizal community of Betula nana in Arctic tundra. Global Change Biol. 17, 1625-1636.

Deslippe, J.R., Hartmann, M., Simard, S.W., Mohn, W.W., 2012. Long-term warming alters the composition of Arctic soil microbial communities. FEMS Microbial Ecology 82, 303-315.

de Witte, L.C., Rosenstock, N.P., van der Linde, S., Braun, S., 2017. Nitrogen deposition changes ectomycorrhizal communities in Swiss beech forests. Sci. Total Environ. 605-606, 1083-1096.

Dieleman, W.I.J., Vicca, S., Dijkstra, F.A., Hadegorn, F., Hovenden, M.J., Larsen, K.S., Janssens, I.A., 2012. Simple additive effects are rare: a quantitative review of plant biomass and soil process responses to combined manipulations of $\mathrm{CO}_{2}$ and temperature. Global Change Biol. 18, 2681-2693.

di Pietro, M., Churin, J.L., Garbaye, J., 2007. Differential ability of ectomycorrhizas to survive drying. Mycorrhiza 17, 547-550.

Ekblad, A., Wallander, H., Godbold, D.L., Cruz, C., Johnson, D., Baldrian, P., Björk, R.G. Epron, D., Kieliszewska-Rokicka, B., Kjöller, R., Kraigher, H., Matzner, E., Neumann, J., Plassard, C., 2013. The production and turnover of extramatrical mycelium of ectomycorrhizal fungi in forest soils: role in carbon cycling. Plant Soil 336, 1-27.

Ekblad, A., Mikusinska, A., Ågren, G.I., Menichetti, L., Wallander, H., Vilgalys, R., Bahr, A., Eriksson, U., 2016. Production and turnover of ectomycorrhizal extrametrical mycelial biomass and necromass under elevated $\mathrm{CO}_{2}$ and nitrogen fertilization. New Phytol. 211, 874-885.

Fernandez, C.W., Koide, R.T., 2014. Initial melanin and nitrogen concentrations control the decomposition of ectomycorrhizal fungal litter. Soil Biol. Biochem. 77, 150-157.

Fernandez, C.W., Langley, J.A., Chapman, S., McCormack, L., Koide, R.T., 2016. The decomposition of ectomycorrhizal fungal necromass. Soil Biol. Biochem. 93, $38-49$.

Fujimura, K.E., Smith, J.E., Horton, T.R., Weber, N.S., Spatafora, J.W., 2005. Pezizalean mycorrhizas and sporocarps in ponderosa pine (Pinus ponderosa) after prescribed fires in eastern Oregon, USA. Mycorrhiza 15, 79-86.

Fujimura, K.E., Egger, K.N., Henry, G.H.R., 2008. The effect of experimental warming on the root-associated fungal community of Salix arctica. ISME J. 2, 105-114.

Gardes, M., Bruns, T.D., 1993. ITS primers with enhanced specificity for basidiomycetes-application of mycorrhizae and rusts. Mol. Ecol. 2, 113-118.

Geml, J., Morgado, L.N., Semenova, T.A., Welker, J.M., Walker, M.D., Smets, E., 2015. Long-term warming alters richness and composition of taxonomic and functional groups of arctic fungi. FEMS (Fed. Eur. Microbiol. Soc.) Microbiol. Ecol. 91 fiv095.

Godbold, D.L., Hoosbeek, M.R., Lukac, M., Cotrufo, M.F., Janssens, I.A., Ceulemans, R., Polle, A., Velthorst, E.J., Scarascia-Mugnozza, G., De Angelis, P., Miglietta, F., Peressotti, A., 2006. Mycorrhizal turnover as a dominant process for carbon input into soil organic matter. Plant Soil 281, 15-24.

Hagenbo, A., Kyaschenko, J., Clemmensen, K.E., Lindahl, B.D., Fransson, P., 2018. Fungal community shifts underpin declining mycelial production and turnover across a Pinus sylvestris chronosequence. J. Ecol. 106, 490-501.

Hao, X. Jiang, R. Chen, T., 2011. Clustering 16S rRNA for OTU prediction: a method of unsupervised Bayesian clustering. Bioinformatics 27, 611-618.

Hendricks, J.J., Mitchell, R.J., Kuehn, K.A., Pecot, S.D., 2016. Ectomycorrhizal fungal mycelia turnover in a longleaf pine forest. New Phytol. 209, 1693-1704.

Hyvönen, R., Ågren, G., Linder, S., Persson, T., Cotrufo, F., Ekblad, A., Freeman, M., Grelle, A., Janssens, I., Jarvis, P.G., Kellomäki, S., Lindroth, A., Loustau, D., Lundmark, T., Norby, R., Oren, R., Pilegaard, K., Ryan, M., Sigurdsson, B., Strömgren, M., van Oijen, M., Wallin, G., 2007. The likely impact of elevated $\left[\mathrm{CO}_{2}\right]$, nitrogen deposition, increased temperature and management on carbon sequestration in temperate and boreal forest ecosystems: a literature review. New Phytol. 173, 463-480.

IPCC. Climate Change, 2007. Synthesis Report. Cambridge University Press, Cambridge, 2007. 73 pp.

Jarvis, P., Linder, S., 2000. Botany: constraints to growth of boreal forests. Nature 405, 904-905.

Jones, M.D., Grenon, F., Peat, H., Fitzgerald, M., Holt, L., Philip, L.J., Bradley, R., 2009. Differences in ${ }^{15} \mathrm{~N}$ uptake amongst spruce seedlings colonized by three pioneer ectomycorrhizal fungi in the field. Fungal Ecology 2, 110-120.

Jones, M.D., Twieg, B.D., Ward, V., Barker, J., Durall, D.M., Simard, S.W., 2010 Functional complementarity of Douglas-fir ectomycorrhizas for extracellular enzyme activity after wildfire or clearcut logging. Funct. Ecol. 24, 1139-1151.

Kendrick, W.B., 1961. Hyphomycetes of conifer leaf litter. Can. J. Bot. 39, 833-835.

Kivlin, S.N., Emery, S.M., Rudgers, J.A., 2013. Fungal symbionts alter plant responses to global change. Am. J. Bot. 100, 1-13.

Koljalg, U., Larsson, K.H., Abarenkov, K., Nilsson, R.H., Alexander, I.J., Eberhardt, U., Erland, S., Hoiland, K., Kjoller, R., Larsson, E., et al., 2005. UNITE: a database providing web-based methods for the molecular identification of ectomycorrhizal fungi. New Phytol. 166, 1063-1068.

Landvik, S., Egger, K.N., Schumacher, S., 1997. Towards a subordinal classification of the Pezizales (Ascomycota): phylogenetic analyses of SSU rDNA sequences. Nord. J. Bot. 17, 403-418.

Langley, J.A., Hungate, B.A., 2003. Mycorrhizal controls on belowground litter quality. Ecology 84, 2302-2312.

Läppelammi-Kuransuu, J., Ostonen, I., Strömgren, M., Nilsson, L.O., Kleja, D.B., Sah, S.P., Helmisaari, H.S., 2013. Effects of long-term temperature and nutrient manipulation on Norway spruce fine roots and mycelia production. Plant Soil
366, 287-303.

Li, Y.J., Sun, D.D., Li, D.D., Xu, Z.F., Zhao, C.Z., Lin, H.H., Liu, Q., 2015. Effects of warming on ectomycorrhizal colonization and nitrogen nutrition of Picea asperata seedlings grown in two contrasting forest ecosystems. Sci. Rep. 5, 17546.

Lin, D., Xia, J., Wan, S., 2010. Climate warming and biomass accumulation of terrestrial plants: a meta-analysis. New Phytol. 188, 187-198.

Luo, Y., 2007. Terrestrial carbon-cycle feedback to climate warming. Annu. Rev. Ecol. Evol. Systemat. 38, 683-712.

Majdi, H., Öhrvik, J., 2004. Interactive effects of soil warming and fertilization on root production, mortality, and longevity in a Norway spruce stand in Northern Sweden. Global Change Biol. 10, 182-188.

Marion, G.M., Henry, G.H.R., Freckman, D.W., Johnstone, J., Jones, G., Jones, M.H. Levesque, E., Molau, U., Molgaard, P., Parson, A.N., Svoboda, J., Virginia, R.A. 1997. Open-top designs for manipulating field temperature in high-latitude ecosystems. Global Change Biol. 3, 20-32.

Mohan, J.E., Cowden, C.C. Baas, P., Dawadi, A., Frankson, P.T., Helmick, K., Hughes, E. Khan, S., Lang, A., Macmuller, M., Taylor, M., Witt, C.A., 2014. Mycorrhizal fungi mediation of terrestrial ecosystem responses to global change: mini-review. Fungal Ecology 10, 3-19.

Moritz, R.E., Bitz, C.M., Steig, E.J., 2002. Dynamics of recent climate change in the arctic. Science 297, 1497-1502.

Nicolás, C., Almeida, J.P., Ellström, M., Bahr, A., Bone, S.E., Rosenstock, N.P., Bargar, J.R., Tunlid, A., Persson, P., Wallander, H., 2017. Chemical changes in organic matter after fungal colonization in a nitrogen fertilized and unfertilized Norway spruce forest. Plant Soil 419, 113-126.

Oksanen, J., Blanchet, G., Kindt, R., Legendre, P., Minchin, P.R., O'Hara, R.B. Simpson, G.L., Solymos, P.M., Stevens, M.H.H., Wagner, H., 2013. Vegan: Community Ecology Package. R Package Version 2.0-9 http://CRAN.R- project.org/ package $=$ vegan

Parrent, J.L., Vilgalys, R., 2007. Biomass and compositional responses of ectomycorrhizal fungal hyphae to elevated $\mathrm{CO}_{2}$ and nitrogen fertilization. New Phytol. $176,164-174$

Peltoniemi, K., Laiho, R., Juottonen, H., Kiikkila, O., Makiranta, P., Minkkinen, K. Pennanen, T., Penttila, T., Sarjala, T., Tuittila, E.S., Tuomivirta, T., Fritze, H., 2015 Microbial ecology in a future climate: effects of temperature and moisture on microbial communities of two boreal fens. FEMS (Fed. Eur. Microbiol. Soc.) Microbiol. Ecol. 91 fiv062.

Pena, R, Lang, C., Lohaus, G, Boch, S., Schall, P. Schoning I, Ammer, C, Fischer, M. Polle, A., 2017. Phylogenetic and functional traits of ectomycorrhizal assemblages in top soil from different biogeographic regions and forest types. Mycorrhiza 27, 233-245.

Pickles, B.J., Genney, D.R., Anderson, I.C., Alexander, I.J., 2012a. Spatial analysis of ectomycorrhizal fungi reveals that root tip communities are structured by competitive interactions. Mol. Ecol. 21, 5110-5123.

Pickles, B.J., Egger, K.N., Massicotte, H.B., Green, D.S., 2012b. Ectomycorrhizas and climate change. Fungal Ecology 5, 73-84.

Qiao, M., Zhang, Z., Li, Y., Xiao, J., Yin, H., Yue, B., Liu, Q., 2016. Experimental warming effects on root nitrogen absorption and mycorrhizal infection in a subalpine coniferous forest. Scand. J. For. Res. 31, 347-354.

R Core Team, 2013. R: a Language and Environment for Statistical Computing v.3.1.2. R Foundation for Statistical Computing, Vienna, Austria. http://www.Rproject.org/.

Rosenstock, N.P., Berner, C., Smits, M.M., Kram, P., Wallander, H., 2016. The role of phosphorus, magnesium and potassium availability in soil fungal exploration of mineral nutrient sources in Norway spruce forests. New Phytol. 211, 542-553.

Rustad, LE, Rustad, J.L. Campbell, G.M. Marion, RJ. Norby, MJ. Mitchell, A.E. Hartley, J.H.C., Cornelissen, J., Gurevitch, J., 2001. A meta-analysis of the response of soil respiration, net nitrogen mineralization, and aboveground plant growth to experimental ecosystem warming. Oecologia 126, 543-562.

Rygiewicz, P.T. Martin, K.J., Tuininga, A.R., 2000. Morphotype community structure of ectomycorrhizas on Douglas fir (Pseudotsuga menziesii Mirb. Franco) seedlings grown under elevated atmospheric $\mathrm{CO}_{2}$ and temperature. Oecologia 124 , 299-308.

Schloss, P.D, Westcott, S.L, Ryabin, T, Hall, J.R, Hartmann, M. Hollister, E.B. Lesniewski, R.A., Oakley, B.B., Parks, D.H., Robinson, C.J., et al., 2009. Introducing mothur: open-source, platform-independent, community-supported software for describing and comparing microbial communities. Appl. Environ. Microbiol. 75, 7537-7541.

Schweigert, M., Herrmann, S., Miltner, A., Fester, T., Kästner, M., 2015. Fate of ectomycorrhizal fungal biomass in a soil bioreactor system and its contribution to soil organic matter formation. Soil Biol. Biochem. 88, 120-127.

Sharkhuu, A., Plante, A.F., Enkhmandal, O., Casper, B.C., Helliker, B.R., Boldgiv, B., Petraitis, P.S., 2013. Effects of open-top passive warming chambers on soil respiration in the semi-arid steppe to taiga forest transition zone in northern mongolia. Biogeochemistry 115, 333-348.

Shi, L., Guttenberger, M., Kottke, I., Hampp, R., 2002. The effect of drought on mycorrhizas of Beech (Fagus sylvatica L.): changes in community structure, and the content of carbohydrates and nitrogen storage bodies of the fungi. Mycorrhiza $12,303-311$.

Siemens, J.A., Zwiazek, J.J., 2008. Root hydraulic properties and growth of balsam poplar (Populus balsamifera) mycorrhizal with Hebeloma crustuliniforme and Wilcoxina mikolae var. mikolae. Mycorrhiza 18, 393-401.

Sigurdsson, B.D., Leblans, N., Oddsdottir, E.S., Maljanen, M., Janssens, I.A., 2014 Effects of geothermal soil warming on soil carbon and nutrient processes in a 
Sitka spruce plantation. Working Papers of the Finnish Forest Research Institute $316,11-13$.

Sigurdsson, B.D., Leblans, N.I.W., Dauwe, S., Guðmundsdóttir, E., Gundersen, P., Gunnhildur, E., Gunnarsdóttir, G.E., Holmstrup, M., Ilieva-Makulec, K. Kätterer, T., Bryndís Marteinsdóttir, B., Marja Maljanen, M., Oddsdóttir, E.S. Ostonen, I., Peñuelas, J., Poeplau, C. Richter, A., Sigurðsson, P., Bodegom, P.V. Wallander, H., Weedon, J., Janssens, I., 2016. Geothermal ecosystems as natural climate change experiments: the ForHot research site in Iceland as a case study Icel. Agric. Sci. 29, 53-71.

Simard, S.W., Jones, M., Durall, D.M., 2002. Carbon and nutrient fluxes within and between mycorrhizal plants. In: van der Heijden, M.G.A., Sanders, I. (Eds.) Mycorrhizal Ecology. Springer, Berlin, pp. 33-91.

Šimonovičová, A., Nováková, A., Pangallo, D., Hnátová, V., Hubka, V., 2014. The occurrence of heat-resistant species of Trichophaea abundans in different types of soil in Slovakia and Czech Republic. Biologia 69, 168-172.

Smith, S.E., Read, D.J., 2008. Mycorrhizal Symbiosis 3rd Edn. Academic Press London.

Staddon, P.L., Heinemeyer, A., Fitter, A.H., 2002. Mycorrhizas and global environmental change: research at different scales. Plant Soil 244, 253-261.

Strömgren, M., Linder, S., 2002. Effects of nutrient and soil warming on stemwood production in a boreal Norway spruce stand. Global Change Biol. 8, 1195-1204.

Tedersoo, L., Suva, T., Larsson, E., Koljalg, U., 2006. Diversity and community structure of ectomycorrhizal fungi in a wooded meadow. Mycol. Res. 110 $734-748$.

Tedersoo, L., May, T.W., Smith, M.E., 2010. Ectomycorrhizal lifestyle in fungi: global diversity, distribution, and evolution of phylogenetic lineages. Mycorrhiza 20 217-263.

Treseder, K.K., Marusenko, Y., Romero-Olivares, A.L., Maltz, M.R., 2016. Experimenta warming alters potential function of the fungal community in boreal forest
Global Change Biol. 22, 3395-3404.

van Mannen, A., Gourbiere, F., 1997. Host and geographical distribution of Verticicladium trifidum, Thysanophora penicilliodes, and similar fungi on decaying coniferous needles. Can. J. Bot. 75, 699-710.

Wallander, H., Nylund, J.E., 1992. Effects of excess nitrogen and phosphorous starvation on extramatrical mycelium in Scots pine seedlings. New Phytol. 120 495-503.

Wallander, H., Nilsson, L.O., Hagerberg, D., Bååth, E., 2001. Estimation of the biomass and seasonal growth of external mycelium of ectomycorrhizal fungi in the field New Phytol. 151, 753-760.

Wallander, H., Johansson, U., Sterkenburg, E., Duling, M.B., Lindahl, B.D., 2010 Production of ectomycorrhizal mycelium peaks during canopy closure in Norway spruce forests. New Phytol. 187, 1124-1134.

Wallander, H., Ekblad, A., Bergh, J., 2011. Growth and carbon sequestration by ectomycorrhizal fungi in intensively fertilized Norway spruce forests. For. Ecol Manag. 262, 999-1007.

White, T.., Bruns, T.D., Lee, S., Taylor, J.W., 1990. Amplification and direct sequencing of fungal ribosomal RNA genes for phylogenetics. In: Innis, M., Gelfand, D. Sninsky, J., White, T. (Eds.), PCR Protocols. A Guide to Methods and Applications Academic Press, Orlando, pp. 315-322.

Wu, Z., Dijkstra, P., Koch, G.W. Penuelas, J., Hungate, B.A., 2011. Responses of terrestrial ecosystems to temperature and precipitation change: a metaanalysis of experimental manipulation. Global Change Biol. 17, 927-942.

Yin, H.J., Xiao, J., Li, Y.F., Chen, Z., Cheng, X.Y., Zhao, C.Z., Liu, Q., 2013. Warming effects on root morphological and physiological traits: the potential consequences on soil C dynamics as altered root exudation. Agric. For. Meteorol. 180 287-296.

Yu, T.E., Egger, K.N., Peterson, L.R., 2001. Ectendomycorrhizal associations - characteristics and functions. Mycorrhiza 11, 167-177. 